\title{
New education strategy in quality measurement technique with image processing technologies - chances, applications and realisation
}

\author{
Maik Rosenberger, Mathias Schellhorn, Gerhard Linß \\ Technische Universität IImenau, Gustav Kirchhoff Platz 2, 98693 IImenau, Germany
}

\begin{abstract}
According to the publication "New education strategy in quality measurement technique with image processing technologies" presented on the $14^{\text {th }}$ Joint International IMEKO TC1+TC7+TC13 Symposium, in this paper further issues were discussed. So the theory of quality charts especially with the use of data sets generated with camera sensors are enlarged in this publication. Furthermore an additional application, developed in the department Quality assurance and Industrial Image Processing was added to this issue. The main focus of this paper lays on the realization, how to combine image processing with classical quality assurance methods. To gain the importance of this trial two industrial applications were used to describe the problem. Mostly the technical realization of sensor systems and data processing is completely separated to quality inspection tasks. To close this gap special trainings as well as special parts in the lectures were developed and structured. In sum it ends to one deepening direction, Opto Techniques in the consecutive Master - Bachelor program Optronic on the IImenau University of Technology.
\end{abstract}

Keywords: quality assurance; control chart; image processing; spring inspection; statistical process control

Citation: Maik Rosenberger, Mathias Schellhorn, Gerhard Linß, "New education strategy in quality measurement technique with image processing technologies - chances, applications and realization", Acta IMEKO, vol. 2, no. 1, article 13, August 2013, identifier: IMEKO-ACTA-02(2013)-01-13

Editors: Paolo Carbone, University of Perugia, Italy; Gerhard Linß, Ilmenau University of Technology, Germany

Received March 27 ${ }^{\text {th }}, 2013$; In final form April 4 ${ }^{\text {th }}, 2013$; Published August 2013

Copyright: (C) 2013 IMEKO. This is an open-access article distributed under the terms of the Creative Commons Attribution 3.0 License, which permits unrestricted use, distribution, and reproduction in any medium, provided the original author and source are credited

Funding: This work was supported by Federal Ministry for Education and Research (BMBF), Germany

Corresponding author: Maik Rosenberger, e-mail: maik.rosenberger@tu-ilmenau.de

\section{INTRODUCTION}

The stability of the production process and whose control technologies, is one of the major topics for the quality of the product. Therefore fast measurement technique plays an important role. Actually more than $80 \%$ of quality assurance applications are realized with image processing so the annual report of the German VDMA association in 2010 [1]. For 2011 the prognosis is an additional increase and an extension to $100 \%$ inspection "Current standard practice in the pharmaceutical industry and in areas such as automobile safety components will become a prerequisite for industrial production as a whole in the future: $100 \%$ quality control rather than random checks - in other words, each and every stage of production will be subject to comprehensive documentation and traceability" [2]. So there is a need for the combination of quality assurance and image processing. On the Ilmenau University of Technology a new way to educate both of them had been started. As one of the first steps to communicate that, the name of the department quality assurance was changed into quality assurance and industrial image processing. Furthermore in the new publication quality management for engineers (Qualitätsmanagement für Ingenieure) a separate chapter for image processing was added in this new publication [3]. After the funding in 1990 two parallel research topics were initiated by the head of the department. So there actual there is a big database and experiences in both research areas, in image processing as well as in quality management.

In the first chapter a short introduction of the new publication (Qualitätsmanagement für Ingenieure) was given, followed by a more detailed look into the statistical process control in section 2. Chapter 3 deals with two special applications where both technologies are combined together. At the end of the paper a strategy was presented which outlines how a teaching model can be, and how it was applied in the department of quality assurance and industrial image processing [3]. 


\section{QUALITY ASSURANCE VERSUS QUALITY MANAGEMENT}

Quality management is the overall process in a company or an institution to monitoring the quality level. Quality assurance means to manufacture material and immaterial products and processes in specified quality, to control and constantly improve processes in specified quality $[1,2,3,4]$. So quality assurance was the technical part of the quality management. To train quality assurance and give the students the possibility to get a better understanding, the main book [3], according to the given lectures and three training books were published.

\section{IMAGE PROCESSING IN THE FIELD OF QUALITY ASSURANCE}

To point out the strong need of the combination of image processing and quality assurance, in the following chapters an example for two industrial applications is given. The methods and the knowledge to realize quality control elements like quality charts, quality loops etc. are contained in the new book. These procedures and the knowledge were applied in this example.

\subsection{Quality control loops}

In analogy to technical control loops therefore quality control loops with Quality Controlled System, Quality Controller and Quality Control Element must be developed. Quality control loops (Figure 1) are defined as closed technological-organizational action sequence in a process for the production of a quality product. With view on the whole production process, quality control loops must be divided into small quality control loops and large quality control loops $[3,5]$. Small quality control loops are used for current control in the production process by instantaneous influencing control on the individual manufacturing steps. They exert direct influence on quality criteria during their production. They include direct statistical process control (SPC) units in the form of quality control charts. As quality reference for example the desired value and the range of tolerance of a quality criterion are consulted [6].

The overall quality control loop includes all activities from the idea of the product up to the line production process. They are used for subsequent inspection and quality confirmation of the production process by delayed influence. In the application, presented in this paper, the small quality control loop is applied [6].

\subsection{Statistical process control with quality control charts}

Statistical process control is a continuous accompanying monitoring of the manufacturing processes by collection of all characteristic numbers relevant for the product quality. SPC supplies the base data for the recognition of weak points and thus the condition for the constant improvement of the respective processes. SPC developed from the quality control charts technique. Quality control charts are one of the oldest tools in the quality management and an important aid to the quality control.

The quality control chart is a form for graphically representing of measured values taken up by sequential samples (Figure 2). They are used for the purpose of the quality control in comparison with warning and/or control limits [7]. The main objective is to recognize promptly error developments for

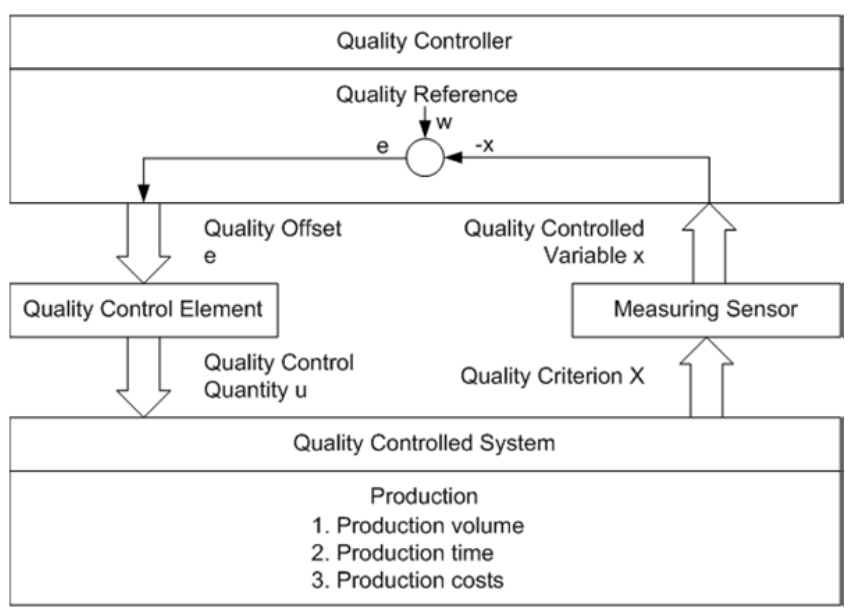

Figure 1. Components and structure of quality control loops [3].

regulative intervention. Examples of quality control charts are shewhart quality control chart, average value quality control chart and median quality control chart. For the definition of the interference and warning limits of quality rule maps the following error bands are used:

$$
\begin{array}{lll}
-\alpha=1 \% & \rightarrow 99 \% \text { error band } & \rightarrow \text { control limit } \\
\text { - } \alpha=5 \% & \rightarrow 95 \% \text { error band } & \rightarrow \text { warning limit }
\end{array}
$$

In the $99 \%$ error band covers at least $99 \%$ of the values of the characteristic. With the fact it is improbable that with an unchanged process values arise, which lie outside of this range. That means, if the values lie within the control and warning limits, the process can be continued without intervention. A Violation of the warning limits leads to a monitoring of the process with increased attention. If the values fall outside the control borders, intervention must take place into the process, in order to guarantee quality of the product. In addition the causes for the change of the process must be examined.

For the successful implementation of SPC four conditions must be fulfilled: data integrity, data traceability, identify critical process parameters and real-time capability [6]. Data integrity means that the measurements must be accurate, so that fluctuations during the process are recognized surely. The traceability to the respective process and product must be secured, so that interferences in the correct place are accomplished. Beyond that the production steps must be recognized, which have a significant influence on product quality. Each intervention into a current process means a interference. The reduction of unnecessary interventions into the process is a goal of the SPC. The presented Inline

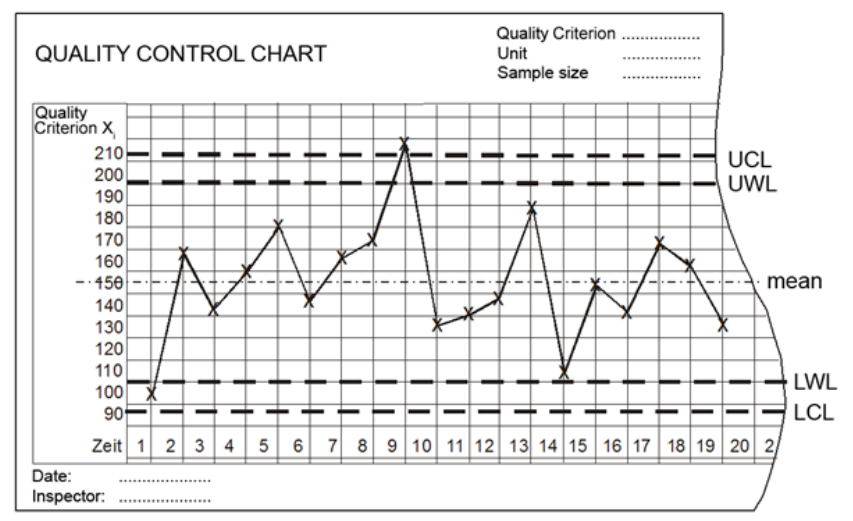

Figure 2. Structure of a quality control chart ( $U C L=$ Upper Control Limit (or Upper Action Limit); LCL = Lower Control Limit (or Lower Action Limit); UWL = Upper Warning Limit; LWL = Lower Warning Limit) [3]. 

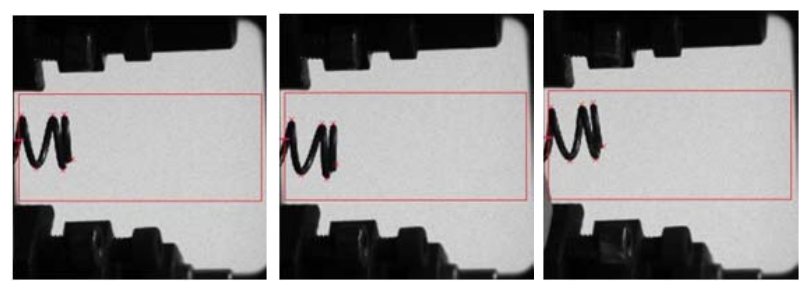

Figure 3. Images of swinging springs (left: horizontally; middle: downward swinging; right: upward swinging) [7].

measuring system on basis of image processing technology fulfils all these conditions [6].

\subsection{Application for a statistical process control using quality assurance and image processing technologies in the quality control of springs}

In the presented application, the quality control chart represents the quality controller in the quality control loop (Figure 2, Figure 5). The set points for the spring production are the length and the diameter. The drives of the production machine and its mechanic system represent the control path. The entry values for the quality control chart deliver an image processing system. So the control loop is closed. Troubles during the control path can be, for example, defective wire or abrasion of the mechanical forming tools.

The novel approach in this application is that the ranges of the quality control chart directly controls the spring forming process. Therefore an upper warning limit and a lower warning limit were defined. Also an upper control limit and a lower control limit were to be used for the control of the process.

Beyond that, the software offers additional support to the operator. In a typical measuring scenario is assumed humans know the item under test and its situation exactly. In the field of technical recognition the algorithm must be able to detect type and orientation of the unit under test.

For humans it is relatively easy to differentiate on a single view cylindrical, single-conical or double-conical springs (Figure 4). The different spring types cover different geometrical boundary conditions, which must be monitored during the production process. The teach-in process of these conditions for inspection is however more difficult for the operator to realize. That leads to the fact, that a manual setting-up of the individual values, depending on the type of spring, increases the danger of operator errors.

In this new approach of software the detection and the classification of the spring type works automatically. The operator only has a one button solution to set up the whole production system. The manual configuration of area of interest (AOI) for the measurement is replaced by the new algorithm. So the operator errors and the teach-in time for new geometric spring forms can be minimized. Another novel algorithm in the software realizes automatic tracking of the measuring points.

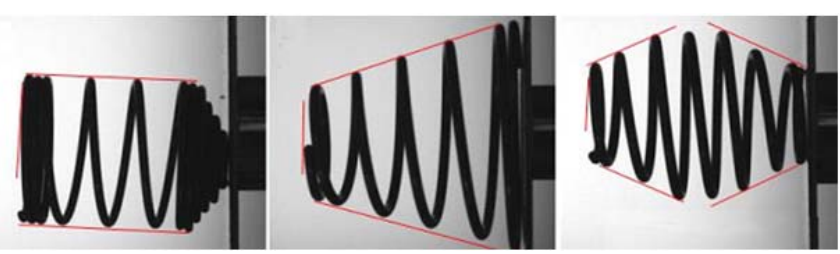

Figure 4. Different spring types left: cylindrical spring; middle: single conical spring; right: double-conical spring).

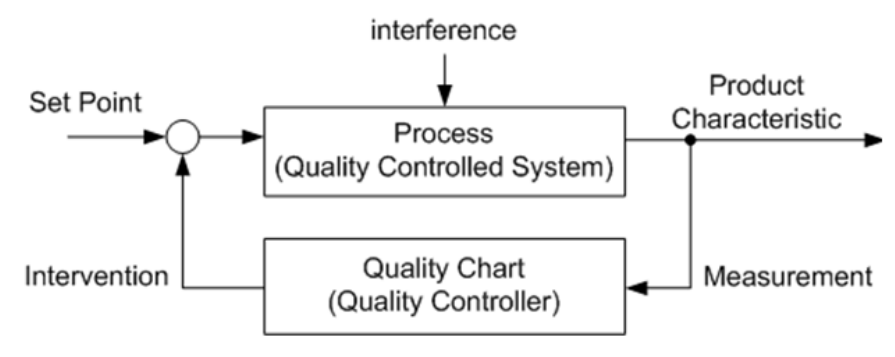

Figure 5. Small quality control loop using quality control charts for SPC.

That means, during the production process the spring can begin to swing and has different orientations. This leads to not deterministically assignable deviations of the spring position of two following springs during the production process (Figure 3). From it results, that the use of static AOI is not possible in such high-dynamic processes. After the machine configuration the software is able to make a good or bad divisor identification based on the set points from the small quality loop. Furthermore the software generates new setup values for the forming tools during the runtime of the machine. In case of a bad divisor identification a sorting device is steered, in order to segregate the incorrect spring.

The software for statistical process control was integrated directly into the machine control software (Figure 6). Algorithms compare the quality controlled variable determined by the measuring system (geometrical dimension) with the quality reference (nominal dimension and tolerance). In the case of a quality offset the drive control is readjusted. Different control algorithms can be realized.

\subsection{Application for quality inspection of mechanical tools}

In the first example the use of quality control charts and the combination of image processing and quality assurance in a bad or good decision application was presented. Another important task is the qualitative measurement of tools or parts during or after the use. Therefore image processing is also a well suited method. In the department a special hardware and software solution for the quality inspection of tool cutting edges (Tool Presetter) were developed. The tool is connected to a rotary axis which is combined with a rotary encoder. So the current angle of the tool can be determined in reference to the

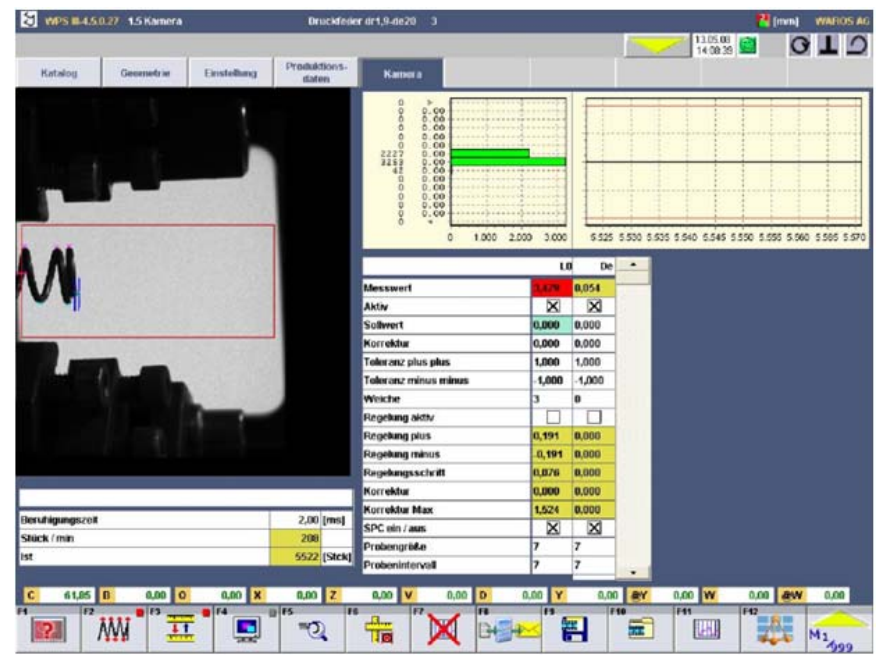

Figure 6. Machine-integrated image processing software with analysed spring and quality control plan. 


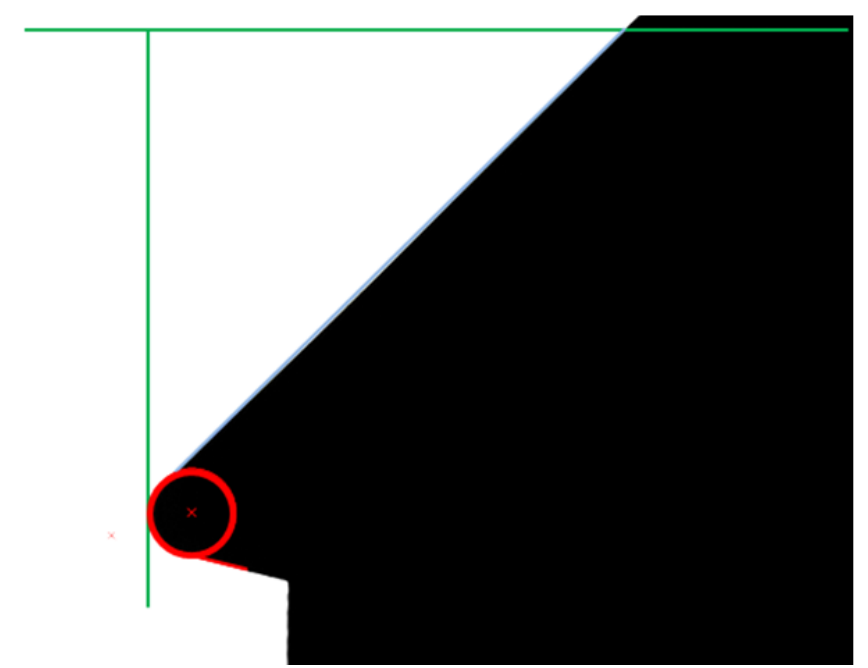

Figure 7. Cutting edge inspection with measurement overlay back illuminated.

basement. Two linear axes also with integrated linear encoders are carrying an image system which is connected with the basement. With the three references axes it is possible to calibrate the image system in reference to a defined reference point. All axes are manual movable by the operator. After an additional calibration of the camera system the operator is able to measure the cutting edges on the tool. During this research several students were embedded in this work. That is one of the options during the lectures and practical tests they have to absolve. So they helping the researchers to solve mechanical tasks like how to arrange the linear bearings, where to install the electrical power supply, electrical tasks like which PC is an optimal solution for this application, as well as testing the devices and programming little parts for the image processing. The result of the joint research is depicted in the Figure 8. On the left upper corner of the left picture the camera system combined with an integrated incident light is illustrated. In the middle of the picture, the telecentric range of the lens, the device under test is placed. Beside the measurement system, a picture captured with this system is presented. The interesting area for the quality inspection shows the diameter and the edges in the near of this range. With this system uncertainty of measurement of less than 1 micron can be achieved. After finishing this demonstrator in software as well as in hardware the option for statistical investigation is given. Figure 7 shows a part of a screenshot during the measuring task. The red circle is the best fit into the interesting radius of this tool. From there it is also possible to calculate the angles which are embedded within the green lines and the blue line. Also the angle between the red line and the blue line is interesting for the sample geometry and can be determined with this system. For the measurement of the features a complex software architecture
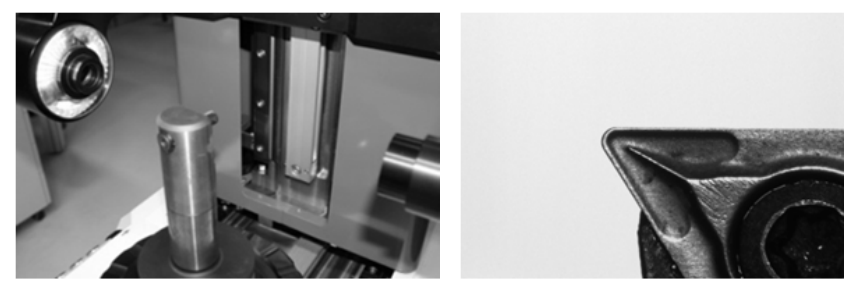

Figure 8. Image processing system in a tool presetter (left), Device under test in the tool presetter (right) [8]. were build, which is possible to handle such tasks very fast and also save the results in a database.

After the measurement data processing, two options are availible to continue with the quality assurance. One option is to send the current data like cutting angle, linear offset etc. via a special interface directly to the computer numerical controlled manufacturing machine. So the control system of the manufacturing centre is able to correct offset errors after the tool is attached to tool changer. This way is similar to statistical process control. The other option saves the quality features of the same tools in the incoming goods inspection, to get information long term stability of the tool manufacturer quality. Once more this additional example shows the importance of the interaction between quality assurance and image processing. All the results of the development and research for that industrial application are directly fed back to the lectures image processing part I and image processing part II as well as to the quality management lectures. Furthermore a few students got the chance to absolve an internship in local companies which working on his type of imaging system.

\section{HOW TO TEACH THE NEW STRATEGY}

First of all the students have to absolve the lectures concerning to quality management. In this part quality

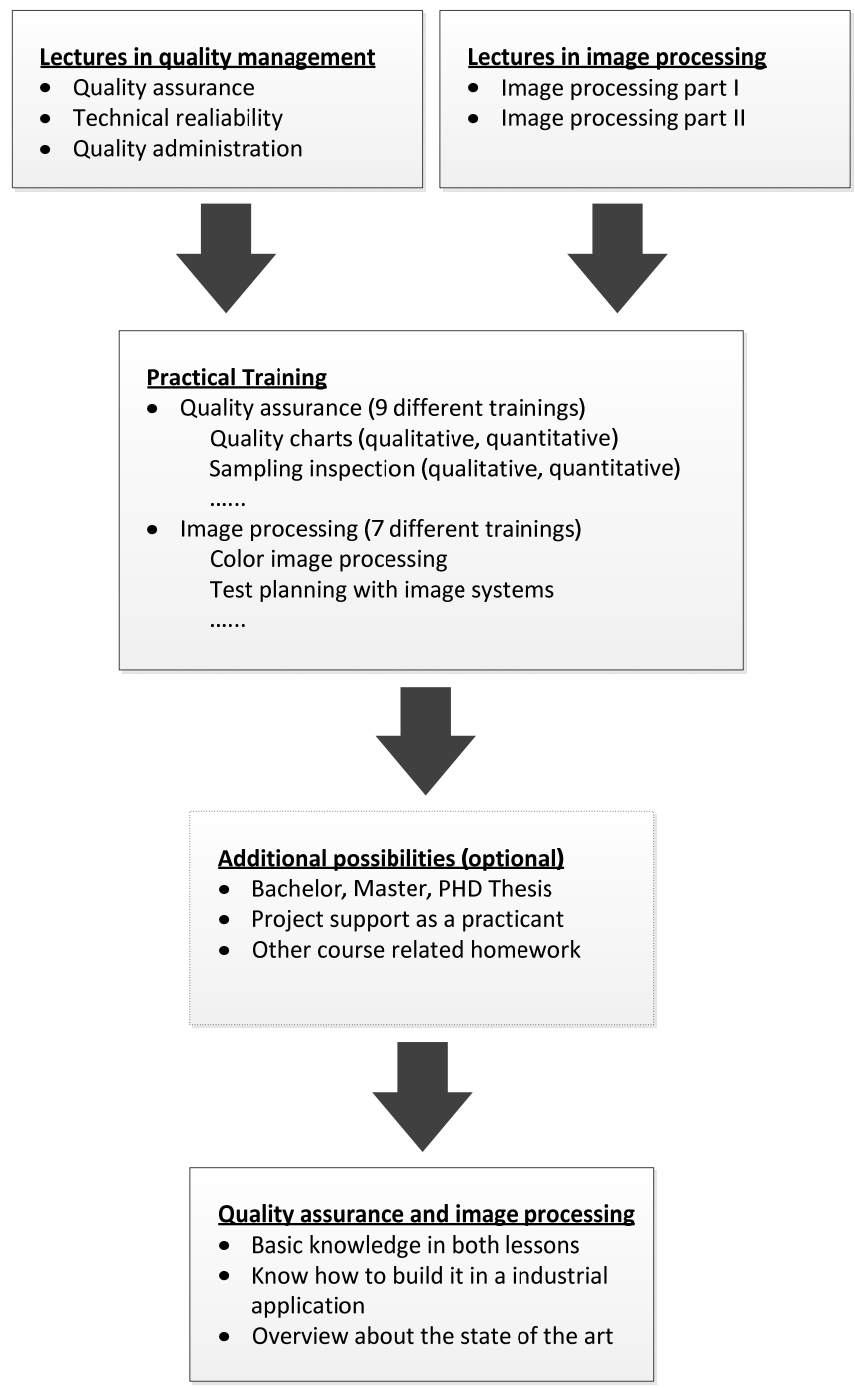

Figure 9. Flow chart education steps in a combined strategy in image processing and quality assurance [9]. 
assurance, technical reliability and quality administration are contained. Simultaneously they have to pass the lectures in industrial image processing part I and part II. If they have done it successfully, they begin with the practical training. It is divided in the basic quality assurance skills training and basic image processing skills training (Figure 9). During the practical training the students get the chance to benefit from actual research projects and realized solutions like the application in the given examples. To learn the theoretical knowledge after the lectures the new publications support them additionally. Afterwards they have the possibility to get deeper in that field of science, absolving their Bachelor, Master or PHD degree in the department [9].

\section{CHANCES AND REALISATION}

Important aspects, teaching this philosophy in the industrial quality management lectures, are that the students have to understand almost the complete operation of complex imaging systems. Moreover students have to understand and learn how to apply the approach of a closed loop control system combining quality assurance with image processing. That leads to the capability to analyse, understand and finding bugs in inside of these systems. Summarized, the global system oriented working; developing and thinking will be trained with this approach. Mentioned in chapter four students have the chance to absolve three different degrees in the field of study Optronic, deepening direction Opto Techniques.

With this field of study the alumnus are well educated for the industrial reality. They have the option to work as a quality systems engineer as well as an application or development engineer in the field of image processing. Local industry requests for alumnus with this education increases in the last time. The study course started in the winter semester 2005. Up to now a few master alumni received their degree in the last three years. The students which done their master thesis in industry or were supported by the department of quality assurance and Industrial Image processing are actually employed and had no problems to get good job offers. The outlook for the coming years according to the requirements of a $100 \%$ quality inspection [2] leads to a high demand of specialists in this application area. That shows that this approach is a good way to combine these technologies and give students good chances on the job market.

\section{CONCLUSION}

Industrial image processing in combination with quality assurance is a powerful method to monitor the quality of industrial processes. In the first given Example a quality control chart combined with a small control loop is used to steering the spring production. The data therefore were captured with an imaging system. Capturing a cutting edge tool and determining the geometric features were discussed in the second industrial example application. These applications gains and shows the need of a combined education in the field of imaging processing and quality assurance. The students which pass the lectures in the department of quality assurance and industrial image processing, gets lectures of quality assurance as well as image processing. So there are able to understand the interdisciplinary working principles of both techniques. The issues in the VDMA reference [2] and the demand of a $100 \%$ quality inspection in industrial applications will be a gaining factor for the establishment of this education strategy. Students which receive a degree will became the makers of industrial quality inspection in the coming years.

\section{REFERENCES}

[1] P. Schwarzkopf, "Der Markt für industrielle Bildverarbeitung in Deutschland”, Industrial VISION Days 2010, 2010, Powerpoint presentation.

[2] VDMA Machine Vision Group within the Robotics + Automation Association, "Key Technology for Automation Solutions Machine Vision 2011/12 Applications - Products Suppliers", Machine Vision, Volume I, 2012, pp. 6-9.

[3] G. Linss, "Qualitätsmanagement für Ingenieure”, Hanser Fachbuchverlag, Munich, 2011, 978-3446-41784-7.

[4] A. Weckenmann, "Verkettete Qualitätsregelkreise auf der Basis systemgerechter Prozess- und Schnittstellenbewertung", Sonderforschungsprojekt 396, Teilprojekt C2, Lehrstuhl Qualitätsmanagement und Fertigungsmesstechnik der FriedrichAlexander-Universität Erlangen-Nürnberg.

[5] P. Profos, T. Pfeifer, "Handbuch der industriellen Messtechnik", R. Oldenbourg Verlag, Munich, 1994, 3-48622537-5.

[6] W. A. Levinson, F. Tumbelty, "SPC essentials and productivity improvement: a manufacturing approach", ASQC Quality Press, Volume I, 1997, p. 97.

[7] H.-P. Jungen, "Werkzeuge und statistische Methoden für das Qualitätsmanagement", Vienna, 1993, pp. 4-6.

[8] Schellhorn M., Rosenberger M., Güttner S., Linß G., "Bildverarbeitungstechnologien für die Qualitätssicherung in der Produktion”, In:Vielfalt Qualität - Tendenzen im Qualitätsmanagement Bericht zur Jahrestagung 2012, Volume I, 2012, pp. 3-17;

[9] G. Linss , M. Rosenberger, M. Schellhorn , P. Werner, S. Lübbecke, "New education strategy in quality measurement technique with image processing technologies", Joint International IMEKO TC1+TC7+TC13 Symposium 2011, Jena, Germany, 2011, urn:nbn:de:gbv:ilm1-2011imeko-040:9. 